\title{
Morphology of rat brain neurons in subtotal ischaemia and introduction of L-NAME and omega-3 polyunsaturated fatty acids
}

\section{Lizaveta Bon \\ Department of Pathological Physiology named after D.A. Maslakov, Grodno State Medical University \\ (iD) https://orcid.org/0000-0002-2380-1586 \\ Corresponding author: asphodela@list.ru}

\section{Natalia Ye. Maksimovich}

Department of Pathological Physiology named after D.A. Maslakov, Grodno State Medical University

(D) https://orcid.org/0000-0003-3181-9513

\section{Sergey M. Zimatkin}

Chair of Histology, Cytology and Embryology, Grodno State Medical University

(iD) https://orcid.org/0000-0001-5728-2588

DOI: https://doi.org/10.20883/medical.e423
Keywords: cerebral ischaemia, parietal cortex, hippocampus, omega-3 polyunsaturated fatty acids, Nw-nitro-L-Arginine Methyl Ester

Published: 2020-09-30

\begin{abstract}
How to cite: Bon L, Maksimovich NY, Zimatkin SM. Morphology of rat brain neurons in subtotal ischaemia and introduction of L-NAME and omega-3 polyunsaturated fatty acids. JMS [Internet]. 2020 Sep 30;89(3):e423. doi:10.20883/medi-
\end{abstract} cal.e423

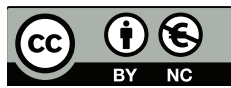

(C) 2020 by the author(s). This is an open access article distributed under the terms and conditions of the Creative Commons Attribution (CC BY-NC) licencse. Published by Poznan University of Medical Sciences

\begin{abstract}
Introduction. Cerebral ischaemia leads to the development of numerous morphofunctional disorders of the cerebral cortex, which can be exacerbated by the introduction of a N $\omega$-nitro-L-arginine methyl ester (L-NAME), which is a non-selective inhibitor of nitric oxide synthase (NOS).

Aim. To study the morphological features of rat brain neurons in subtotal ischaemia during the administration of L-NAME and naturally occurring omega-3 polyunsaturated docosahexaenoic acid (DHA).

Material and Methods. Subtotal cerebral ischaemia was modelled in rats by ligation of both common carotid arteries. L-NAME and DHA were given individually or in combination to separate groups of rats. L-NAME $(5 \mathrm{mg} / \mathrm{kg})$ was administered intramuscularly immediately before ligation and DHA $(5 \mathrm{mg} / \mathrm{kg})$ intragastrically during the week before ligation.

Results. The introduction of DHA alone had a corrective effect on the hippocampus under conditions of subtotal ischaemia, reducing the number of shadow cells and hyperchromic wrinkled neurons, without significantly affecting the size and shape of the neurons of the parietal cortex. However, the previous administration of DHA to rats with cerebral ischaemia receiving a NOS inhibitor did not abrogate the negative effects on the state of the neurons in the cerebral cortex.

Conclusion. The administration of DHA can modulate the morphological disorder of the hippocampus which occurs in subtotal cerebral ischaemia.
\end{abstract}

\section{Introduction}

Stroke is one of the most pressing problems in modern medicine $[1,2]$. Cerebrovascular diseases of ischaemic origin tend to grow, rejuvenate and are associated with a severe clinical course, high rates of disability, and mortality. The frequency of acute cerebrovascular accidents varies from 1 to 
4 cases per 1,000 population per year. Cerebrovascular injuries are critical, requiring the concentrated efforts of different specialists, as well as the search for new approaches for the treatment of the disorders of ischaemic brain genesis [2]. One of the promising directions for solving this issue is to inhibit the formation of nitric oxide (NO). NO acts as a free radical therefore can exhibit both anti- and prooxidant properties, affecting vascular tone, haemostasis, and inflammation, showing dual effects. The non-selective inhibitor of NO synthase (NOS), N $\omega$-nitroL-arginine methyl ester (L-NAME) inhibits all isoforms of the enzyme, including endothelial, which leads to a decrease in antihypoxic resistance, an increase in platelet aggregation, and a decrease in cerebral blood flow $[3,4]$.

Omega-3 polyunsaturated fatty acids (Omega-3) can have a corrective effect on the state of the endothelium, reducing the severity of oxidative stress by activating antioxidant enzymes (catalase, superoxide dismutase, glutathione per-

\section{Material and Methods}

Studies were performed on 30 male outbred white rats weighing $210 \pm 20 \mathrm{~g}$ according to the requirements of the Directive of the European Parliament and the Council No. 2010/63 / EU of 09.22.2010 on the protection of animals used for scientific purposes. Protocols were reviewed and approved by the Ethical Committee of the Grodno State Medical University (protocol No 1, 14.04.2013). The animals were kept in the vivarium in a ventilated room at $22^{\circ} \mathrm{C}, 50 \%$ humidity and illumination not more than 25 luxin, with no more than five rats per cage. The animals were fed cereals and legumes (oats, millet, barley, peas) and succulent feed (carrots, beets, cabbage) three times a day and had easy access to food and water.

The rats were divided into five groups, with six rats per group as described in Table 1. Subtotal cerebral ischaemia (SCl) was modelled by ligation of both common carotid arteries under conditions of intravenous thiopental anaesthe-

Table 1. Experimental scheme

\begin{tabular}{ll}
\multicolumn{1}{c}{ Animal group } & \multicolumn{1}{c}{ Experimental scheme } \\
\hline Control & false-operated rats received $0.5 \mathrm{ml}$ of isotonic $\mathrm{NaCl}$ solution \\
\hline Group 1: $\mathrm{SCl}$ & $\begin{array}{l}\text { ligation of both common carotid arteries under conditions of intravenous thiopental } \\
\text { anaesthesia }(40-50 \mathrm{mg} / \mathrm{kg})\end{array}$ \\
\hline Group 2: $\mathrm{SCl}+\mathrm{L}-\mathrm{NAME}$ & L-NAME was administered intramuscularly at a dose of $5 \mathrm{mg} / \mathrm{kg}$ immediately before $\mathrm{SCl}$ \\
\hline Group 3: $\mathrm{SCl}+\mathrm{L}-\mathrm{NAME}+\mathrm{DHA}$ & $\begin{array}{l}\text { L-NAME was administered intramuscularly at a dose of } 5 \mathrm{mg} / \mathrm{kg} \text { immediately before } \mathrm{SCl} \\
\text { and DHA }(5 \mathrm{mg} / \mathrm{kg}) \text { administered intragastrically during the week before surgery }\end{array}$ \\
\hline Group 4: $\mathrm{SCl}+\mathrm{DHA}$ & $\begin{array}{l}\text { were additionally given intragastrically during the week before } \mathrm{SCl} \text { with DHA at a dose } \\
\text { of } 5 \mathrm{mg} / \mathrm{kg} \text { body weight }\end{array}$ \\
\hline
\end{tabular}

oxidase, and glutathione transferase), as well as acting as free radical scavengers $[5,6]$. The action of Omega-3 is associated with their effect on the function of cell membranes, transmembrane ion channels and the regulation of physiological processes. Furthermore, Omega-3 is involved in the implementation of basic neuronal functions, such as impulse transmission and receptor activation. Brain neurons, being electrically active cells rich in ion channels, are most sensitive to Omega-3 deficiency [7].

This study aimed to investigate the morphological characteristics of neurons of the parietal cortex and hippocampus of rats with subtotal cerebral ischaemia against the background of the administration of Omega-3 and L-NAME. sia $(40-50 \mathrm{mg} / \mathrm{kg}$ ). L-NAME was administered intramuscularly immediately before $\mathrm{SCl}$ at a dose of $5 \mathrm{mg} / \mathrm{kg}$. Docosahexaenoic acid (DHA) in the form of a microalgae Schizochytrium sp. (Polski Lek S.A., Poland) preparation at a dose of $0,5 \mathrm{~g} / \mathrm{kg}$ was given intragastrically during the week before $\mathrm{SCl}$. The control group consisted of false-operated rats treated with $0.5 \mathrm{ml}$ isotonic $\mathrm{NaCl}$ solution.

The duration of the surgery to induct $\mathrm{SCl}$ was 60 minutes, after which the rats were decapitated. Samples of the anterior cortex of the cerebral hemispheres were quickly fixed in Carnoy's fluid to study the morphological changes in the neurons of the parietal cortex and CA1 field of the hippocampus in rats after $\mathrm{SCl}$. Serial paraf- 
fin sections were stained with $0.1 \%$ toluidine blue according to the Nissl method.

The microphotography, morphometry, and densitometry of chromogen sediment in histological preparations were performed using an Axioscop 2 plus microscope (Zeiss, Germany), a digital video camera (LeicaDFC 320, Germany) and ImageWarp image analysis programme (Bitflow, USA). The localisation of the parietal cortex and the hippocampus cortex was determined using a stereotactic atlas [9]. At least 30 neurons of the fifth layer of the parietal cortex and the pyramidal layer of the CA1 field of the hippocampus were evaluated in each animal, which ensured a sufficient sample size for subsequent analysis. The number of large pyramidal neurons per unit area of paraffin sections of the cerebral cortex was determined. Cells were distinguished by the intensity of cytoplasm (chromatophilia) staining: normochromic - moderately stained, hyperchromic - dark, hyperchromic shrunken very dark, with deformed perikaryons, hypochromic - lightly stained and shadow cells - almost transparent. The number of cells of each type per $1 \mathrm{~mm}^{2}$ of brain tissue was counted. The size and shape of neuronal perikaryons were determined by area, form factor, and elongation factor.

Non-parametric statistical methods were used for data analysis (Statistica 10.0 software for Windows, StatSoft, Inc., USA) and the results are presented as Me (LQ; UQ), where $\mathrm{Me}$ is the median, $L Q$ is the boundary of the lower quartile and $U Q$ is the boundary of the upper quartile. The comparison between analysed groups was performed by Kruskal-Wallis test with post-hoc Dunn's tests. All tests were considered significant at $p<0.05$.

\section{Results}

The dimensions and shape of perikaryon neurons of the parietal cortex and hippocampus are shown in Table 2. The morphometry of the neurons in group $1(\mathrm{SCl})$ revealed a significant decrease in the area of their perikaryons by $53 \%$ and $49 \%$, with a $20 \%$ increase in elongation in each of the studied sections of the cerebral cortex, and an $11 \%$ and $22 \%$ decrease in roundness, respectively. It is assumed that these changes in the size and shape of neurons are due to water-
Table 2. Dimensions and shape of perikaryon neurons of the parietal cortex and hippocampus of rats

\begin{tabular}{|c|c|c|}
\hline \multirow[t]{2}{*}{ Animal group } & \multicolumn{2}{|c|}{ Brain departments } \\
\hline & parietal cortex & hippocampus \\
\hline \multicolumn{3}{|c|}{ area, $\mathrm{mkm}^{2}$} \\
\hline Control & $145(130 ; 154)^{b}$ & $109(100 ; 122)^{b}$ \\
\hline $\mathrm{SCl}$ & $69(67 ; 74)^{\mathrm{a}}$ & $56(55 ; 57)^{\mathrm{a}}$ \\
\hline SCI + L-NAME & $69(59 ; 79)^{\mathrm{a}}$ & $52(38 ; 58)^{\mathrm{a}}$ \\
\hline $\mathrm{SCl}+\mathrm{DHA}$ & $68(50 ; 84)^{a}$ & $58(53 ; 84)^{a}$ \\
\hline $\mathrm{SCI}+\mathrm{L}-\mathrm{NAME}+\mathrm{DHA}$ & $68(54 ; 80)^{a}$ & $57(40 ; 60)^{\mathrm{a}}$ \\
\hline \multicolumn{3}{|c|}{ form factor, units } \\
\hline Control & $0,9(0,9 ; 0,9)^{b}$ & $0,9(0,9 ; 0,9)^{b}$ \\
\hline $\mathrm{SCl}$ & $0,8(0,8 ; 0,8)^{\mathrm{a}}$ & $0,7(0,7 ; 0,8)^{\mathrm{a}}$ \\
\hline SCI + L-NAME & $0,7(0,6 ; 0,7)^{\mathrm{a}}$ & $0,8(0,8 ; 0,8)^{\mathrm{a}}$ \\
\hline $\mathrm{SCl}+\mathrm{DHA}$ & $0,7(0,7 ; 0,8)^{\mathrm{a}}$ & $0,8(0,6 ; 0,8)^{\mathrm{a}}$ \\
\hline $\mathrm{SCl}+\mathrm{L}-\mathrm{NAME}+\mathrm{DHA}$ & $0,7(0,7 ; 0,8)^{\mathrm{a}}$ & $0,8(0,7 ; 0,8)^{\mathrm{a}}$ \\
\hline \multicolumn{3}{|c|}{ elongation factor, units } \\
\hline Control & $1,2(1,1 ; 1,3)^{a}$ & $1,2(1,1 ; 1,3)^{\mathrm{a}}$ \\
\hline $\mathrm{SCl}$ & $1,5(1,4 ; 1,5)^{b}$ & $1,5(1,4 ; 1,6)^{b}$ \\
\hline SCI + L-NAME & $1,7(1,5 ; 1,8)^{b}$ & $1,7(1,6 ; 1,8)^{b}$ \\
\hline $\mathrm{SCl}+\mathrm{DHA}$ & $1,4(1,4 ; 1,5)^{b}$ & $1,4(1,4 ; 1,4)^{b}$ \\
\hline $\mathrm{SCI}+\mathrm{L}-\mathrm{NAME}+\mathrm{DHA}$ & $1,5(1,5 ; 1,5)^{b}$ & $1,5(1,4 ; 1,6)^{b}$ \\
\hline
\end{tabular}

$\mathrm{a}, \mathrm{b}$ - groups followed by the same letter do not differ statistically significantly

electrolyte abnormalities, as well as the denaturation of the protein inside the cell, which forms the basis of the neurofibrils.

In group 2 (SCI + L-NAME), the form factor decreased by $22 \%$ in the neurons of the parietal cortex compared to group 1 (SCl). Compared with the control group, the area of neurons decreased by $52 \%$, the form factor by $22 \%$, and the elongation factor of neurons increased by $29 \%$ in the parietal cortex. No changes were detected in the hippocampus, and compared with the control group, there was a $52 \%$ decrease in perikaryon area and $11 \%$ decrease in the factor form, with a $29 \%$ increase in the elongation factor.

Compared to the control, in the parietal cortex of group 3, the area of neurons decreased by $53 \%$, the form factor by $22 \%$, and the elongation factor of neurons increased by $20 \%$, whereas in the hippocampus, the area of neurons decreased by $48 \%$, the form factor by $11 \%$, and the elongation factor of neurons increased by $20 \%$.

In the group $4(\mathrm{SCl}+\mathrm{L}-\mathrm{NAME}+\mathrm{DHA})$, there were no significant different area of neurons decreased by $53 \%$, the form factor by $22 \%$, and the elongation factor of neurons increased by $20 \%$ compared with those in the group 1 (SCl) and group 2 (SCI + L-NAME). 
Regarding the chromatophilia of neurons in animals of the $\mathrm{SCl}$ group, there was a decrease in the number of normochromic neurons and an increase in the number of hyperchromic neurons, as well as degenerative forms, hyperchromic shrunken neurons and shadow cells in both the parietal cortex and the hippocampus (Table 3, Figure 1).

In the group $1(\mathrm{SCl})$ in the parietal cortex, the number of hyperchromic neurons increased by $79 \%$, hyperchromic shrunken cells by $80 \%$, shadow cells by $67 \%$. The hippocampus showed a $77 \%$ increase in the number of hyperchromic neurons, hyperchromic shrunken cells by $80 \%$, and shadow cells by $67 \%$ compared to the control group.

In animals of group 2 (SCI + L-NAME), there was a $22 \%$ decrease in the number of hyperchromic neurons in the parietal cortex and a $17 \%$ increase in the number of hyperchromic shrunken neurons compared with the $\mathrm{SCl}$ group and in comparison to the control group, there was a $40 \%$ decrease in the number of normochromic neurons, an $73 \%$ increase in the number of hyperchromic neurons, hyperchromic shrunken neu- rons by $83 \%$ and shadow cells by $67 \%$. There were no changes in the hippocampus compared with the $\mathrm{SCl}$ group but a $31 \%$ decrease in the number of normochromic neurons and a $79 \%$ increase in the number of hyperchromic neurons, hyperchromic shrunken by $82 \%$ and shadow cells by $67 \%$ compared with the control group.

Compared with the controls, the hippocampus of animals in group 3 ( $\mathrm{SCl}+\mathrm{DHA})$ showed a $75 \%$ decrease in the number of hyperchromic shrunken neurons and an $84 \%$ increase in the number of hyperchromic neurons. Compared with the SCl group, there was a $20 \%$ decrease in the number of hyperchromic shrunken neurons, with a $31 \%$ increase in the number of hyperchromic neurons. This indicates the ability of DHA to correct the morphological changes induced in rats with $\mathrm{SCl}$. No differences were observed between the parietal cortex of animals in group $4(\mathrm{SCl}+\mathrm{L}-\mathrm{NAME}$ $+\mathrm{DHA}$ ) compared with the $\mathrm{SCl}$ and $\mathrm{SCI}+\mathrm{L}-\mathrm{NAME}$ groups, which indicates that DHA cannot correct the morphological changes in rats with $\mathrm{SCl}$ administered a NOS inhibitor.

Table 3. The number of different forms of neurons per $1 \mathrm{~mm}^{2}$ by the degree of chromatophilia of the cytoplasm of the parietal cortex and hippocampus

Animal group

\begin{tabular}{|c|c|c|}
\hline & \multirow{2}{*}{\multicolumn{2}{|c|}{ hippocampus }} \\
\hline & & \\
\hline \multicolumn{3}{|c|}{ normochromic neurons } \\
\hline Control & $3208(3178 ; 3245)^{b}$ & $3003(2989 ; 1945)^{b}$ \\
\hline $\mathrm{SCl}$ & 1932(1920; 1945) ${ }^{a}$ & $2062(2009 ; 2298)^{a}$ \\
\hline SCI + L-NAME & 1928(1910; 1960) ${ }^{\mathrm{a}}$ & $2075(2004 ; 2345)^{\mathrm{a}}$ \\
\hline $\mathrm{SCl}+\mathrm{DHA}$ & $2143(1942 ; 2143)^{a}$ & $2052(2001 ; 2167)^{a}$ \\
\hline $\mathrm{SCl}+\mathrm{L}-\mathrm{NAME}+\mathrm{DHA}$ & $1942(1932 ; 2143)^{a}$ & $2135(2001 ; 2269)^{a}$ \\
\hline \multicolumn{3}{|c|}{ hyperchromic neurons } \\
\hline Control & $201(201 ; 268)^{\mathrm{a}}$ & $167(134 ; 201)^{a}$ \\
\hline $\mathrm{SCl}$ & $938(804 ; 938)^{c}$ & $737(670 ; 938)^{b}$ \\
\hline SCI + L-NAME & $737(670 ; 737)^{\mathrm{b}}$ & $807(807 ; 874)^{\mathrm{b}}$ \\
\hline $\mathrm{SCl}+\mathrm{DHA}$ & $1072(804 ; 1072)^{c}$ & $1072(1072 ; 1140)^{c}$ \\
\hline $\mathrm{SCI}+\mathrm{L}-\mathrm{NAME}+\mathrm{DHA}$ & $804(737 ; 1072)^{c}$ & $804(804 ; 938)^{b}$ \\
\hline \multicolumn{3}{|c|}{ hyperchromic shrunken neurons } \\
\hline Control & $134(67 ; 134)^{\mathrm{a}}$ & $134(0 ; 134)^{\mathrm{a}}$ \\
\hline $\mathrm{SCl}$ & $670(670 ; 670)^{b}$ & $670(670 ; 670)^{c}$ \\
\hline SCI + L-NAME & $806(806 ; 806)^{c}$ & $739(672 ; 807)^{c}$ \\
\hline $\mathrm{SCl}+\mathrm{DHA}$ & $603(536 ; 670)^{b}$ & $536(536 ; 536)^{b}$ \\
\hline $\mathrm{SCl}+\mathrm{L}-\mathrm{NAME}+\mathrm{DHA}$ & $670(536 ; 870)^{b}$ & $603(603 ; 672)^{c}$ \\
\hline \multicolumn{3}{|c|}{ shadow cells } \\
\hline Control & $134(0 ; 134)^{\mathrm{a}}$ & $134(134 ; 134)^{\mathrm{a}}$ \\
\hline $\mathrm{SCl}$ & $404(269 ; 404)^{b}$ & $402(269 ; 402)^{b}$ \\
\hline SCI + L-NAME & $404(269 ; 404)^{b}$ & $404(269 ; 404)^{b}$ \\
\hline $\mathrm{SCl}+\mathrm{DHA}$ & $269(269 ; 404)^{b}$ & $134(134 ; 269)^{\mathrm{a}}$ \\
\hline $\mathrm{SCl}+\mathrm{L}-\mathrm{NAME}+\mathrm{DHA}$ & $404(404 ; 404)^{b}$ & $335(269 ; 404)^{b}$ \\
\hline
\end{tabular}

a, b, c - groups followed by the same letter do not differ statistically significantly 

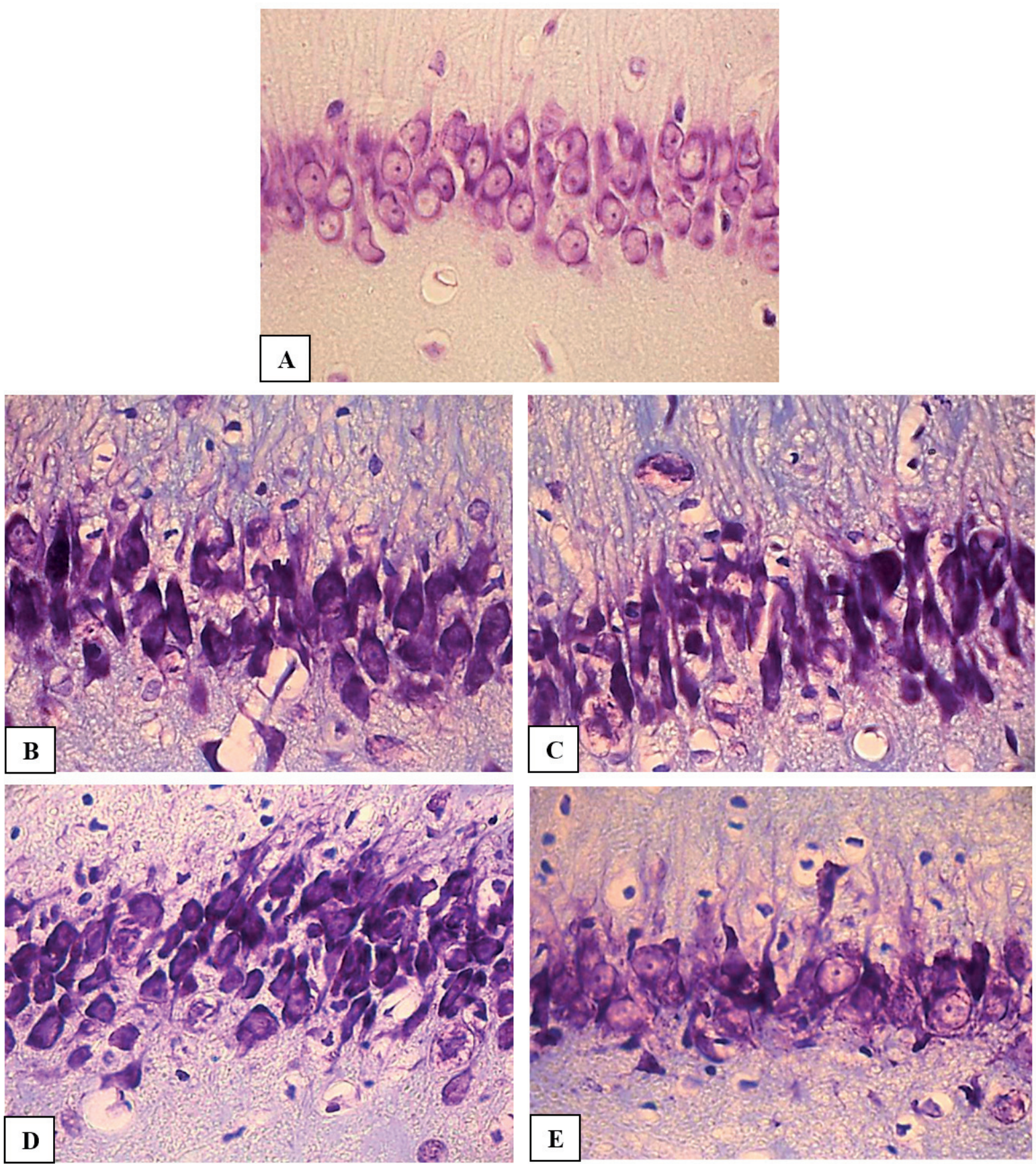

Figure 1. Neurons of the pyramidal layer CA1 of the rat hippocampus stained by Nissl. A - control, B - SCI, C - SCI + L-NAME, D - SCI + L-NAME + DHA, E - SCI + DHA. Scale bars and magnifications: A - $20 \mu \mathrm{m}, \mathrm{X} 400$

\section{Discussion}

Subtotal cerebral ischaemia induces significant morphological changes in the parietal cortex such as a decrease in the size and deformation of the perikaryons of neurons, the appearance of a large number of hyperchromic neurons, as well as the appearance of degenerative forms (hyperchromic shrunken neurons and shadow cells). Hyperchromic neurons are often regarded as markers of ischaemia $[9,10]$ and the intense staining of their cytoplasm is due to a significant predominance of the fraction of free ribosomes forming large clusters. The fixation of ribosomes to the membranes of the granular endoplasmic reticulum is an energy-dependent process provided by the ribophorin protein. Therefore, the degranulation of cisterns of the granular endo- 
plasmic reticulum indicates increasing energy deficiency due to hypoxia. Degenerative changes in the granular endoplasmic reticulum lead to the accumulation of proteins in the cytoplasm, which denature under the influence of developing hypoxia and acidosis. Shrinkage of neurons in the cerebral cortex is the result of water loss due to energy and ionic disorders that decrease the size and increases the deformation of perikaryons. Hyperchromic shrunken neurons lose their functional activity and are subsequently phagocytosed by microglia [9]. The appearance of shadow cells is the next stage of hypochromia, the cause of which is oedema due to electrolyte changes caused by energy deficiency [11].

The introduction of a non-selective inhibitor of NO synthase L-NAME exacerbated the histological disorders of neurons that occur during $\mathrm{SCl}$ : an increase in the number of hyperchromic shrunken neurons, a decrease in size and deformation of their perikaryons. This effect may be due to an increasing degree of ischaemia due to decreased formation of NO, primarily in the endothelium and neurons, which impedes the development of vasodilator compensatory reactions $[3,4]$. This leads to the progression of disturbances in cellular metabolism, aggravation of water-electrolyte imbalance, manifested by deformation of neuron bodies, their wrinkling, and swelling $[1,10]$.

Hippocampal neurons, as a phylogenetically more ancient part of the cerebral cortex, are less sensitive to hypoxia, therefore in this part of the brain, DHA had a corrective effect in rats with $\mathrm{SCl}$, reducing the number of pathological forms of neurons (hyperchromic shrunken and shadow cells). A favourable effect on the state of hippocampal neurons in conditions of subtotal cerebral ischaemia may be due to a decrease in the production of thromboxane $A_{2}$ by platelets, an increase in the level of tissue plasminogen activator, and improved erythrocyte membrane fluidity, which leads to a decrease in viscosity and improved rheological properties of blood and cerebral circulation in general. DHA also exerts anti-inflammatory effects due to the incorporation of monocytes, leukocytes, endothelial cells into the phospholipid layer of the cell membranes, which is accompanied by a decrease in the production of inflammatory mediators and adhesion of leukocytes to the endothelial wall. In addition, Omega- 3 affects the synthesis of prostaglandins that regulate vascular tone and inhibit vasoconstriction of blood vessels under the influence of catecholamines [5-7, 12-15].

Docosahexaenoic acid is involved in the biosynthesis of tissue hormones such as resolvin, which inhibits inflammation and neuroprotectin D1, an endogenous neuroprotector with antiapoptotic activity [7]. However, the administration of DHA to rats with $\mathrm{SCl}$ treated with a NOS inhibitor did not have a corrective effect on the neurons of the parietal cortex and hippocampus of rats.

The limitations of this study are due to the impossibility of following the dynamics of the adaptation of the brain during ischaemia and the metabolic changes of neurons [7].

\section{Conclusion}

Subtotal cerebral ischaemia leads to the development of morphofunctional disorders of the cerebral cortex, which can be modulated with the administration of DHA, reducing the number of shadow cells and hyperchromic wrinkled neurons, without significantly affecting the size and shape of the neurons of the parietal cortex.

\section{Acknowledgements}

\section{Conflict of interest statement}

The authors declare no conflict of interest.

\section{Funding sources}

There are no sources of funding to declare.

\section{References}

1. Maksimovich NY, Pronko TP, Maksimovich YN, Yermak VV. Epidemiology of ischemic strokes in the Grodno region (Belarus). Cerebrovascular Diesases. 2015 Jan 170-170;39.

2. Igorevna Bon L. Effects of Experemental Cerebral Ishemia on Metabolic Characteristics of Parietal Cortex Neurons. Bioprocess Engineering. 2018;2(1):1. https://doi.org/10.11648/j.be.20180201.11

3. Maksimovich N, Zinchuk V, Maslacov D. The degree of oxidative stress in the rat brain during ischemia and reperfusion in conditions of correction of the L-arginine-NO system. Neuroscience and Behavioral Physiol. 2006;36(4):373-8.

4. Maksimovich $\mathrm{N}$. Tolerance of hypoxic hypoxia in rats with cerebral ischaemia treated by $\mathrm{NO}$-synthase modulators. Hypoxia Medical. 2004;V(1-2):20-3.

5. Kaliannan K, Li X, Wang B, Pan Q, Chen C, Hao L, Xie $\mathrm{S}$, Kang JX. Multi-omic analysis in transgenic mice implicates omega-6/omega-3 fatty acid imbalance as a risk factor for chronic disease. Communications 
Biology. 2019 Jul 26;2(1). https://doi.org/10.1038/ s42003-019-0521-4

6. Khunt D, Shrivas M, Polaka S, Gondaliya P, Misra M. Role of Omega-3 Fatty Acids and Butter Oil in Targeting Delivery of Donepezil Hydrochloride Microemulsion to Brain via the Intranasal Route: a Comparative Study. AAPS PharmSciTech. 2020 Jan 3;21(2). https://doi.org/10.1208/s12249-019-1585-7

7. Kangari $H$, Eftekhari $M H$, Sardari $S$, Hashemi $H_{\text {, }}$ Salamzadeh J, Ghassemi-Broumand M, Khabazkhoob M. Short-term Consumption of Oral Omega-3 and Dry Eye Syndrome. Ophthalmology. 2013 Nov;120(11):2191-2196. https://doi.org/10.1016/j. ophtha.2013.04.006

8. Wu B, Song Q, Zhang Y, Wang C, Yang M, Zhang J, Han $W$, Jiang $P$. Antidepressant activity of $\omega-3$ polyunsaturated fatty acids in ovariectomized rats: role of neuroinflammation and microglial polarization. Lipids in Health and Disease. 2020 Jan 8;19(1). https://doi. org/10.1186/s12944-020-1185-2

9. Paxinos G, Watson C. The Rat Brain in Stereotaxic Coordinates. 6. Australia: Academic Press; 1998.

10. Gallyas F, Pál J, Bukovics P. Supravital microwave experiments support that the formation of "dark" neu- rons is propelled by phase transition in an intracellular gel system. Brain Research. 2009 May;1270:152156. https://doi.org/10.1016/j.brainres.2009.03.020

11. Zimatkin SM, Bon El. Dark Neurons of the Brain. Neuroscience and Behavioral Physiology. 2018 Oct;48(8):908-912. https://doi.org/10.1007/s11055018-0648-7

12. Shahidi F, Ambigaipalan P. Omega-3 Polyunsaturated Fatty Acids and Their Health Benefits. Annual Review of Food Science and Technology. 2018 Mar 25;9(1):345-381. https://doi.org/10.1146/annurevfood-111317-095850

13. Grosso G, Galvano F, Marventano S, Malaguarnera M, Bucolo C, Drago F, Caraci F. Omega-3 Fatty Acids and Depression: Scientific Evidence and Biological Mechanisms. Oxidative Medicine and Cellular Longevity. 2014;2014:1-16. https://doi.org/10.1155/2014/313570

14. Serini S, Calviello G. Long-chain omega-3 fatty acids and cancer. Current Opinion in Clinical Nutrition \& Metabolic Care. 2018 Mar;21(2):83-89. https://doi. org/10.1097/mco.0000000000000439

15. Rogers T, Seehusen D. Omega-3 Fatty Acids and Cardiovascular Disease. Am Fam Physician. 2018;97(9):562-4. 